\title{
Successful outcome of severe COVID-19 in pregnancy: individualised approach
}

\author{
Anupama Dave (1) , ${ }^{1}$ Priyansha Joshi, ${ }^{1}$ Sunil Jaiswal, ${ }^{2}$ Pradnya Kapdeo ${ }^{1}$
}

${ }^{1}$ Obstetrics and Gynaecology, Mahatma Gandhi Memorial Medical College, Indore, Madhya Pradesh, India

2Pathology, Mahatma Gandhi Memorial Medical College, Indore, Madhya Pradesh, India

\section{Correspondence to}

Dr Anupama Dave;

anupamadave10@gmail.com

Accepted 31 December 2021

Check for updates

(c) BMJ Publishing Group Limited 2022. No commercial re-use. See rights and permissions. Published by BMJ.

To cite: Dave A, Joshi P, Jaiswal $S$, et al. BMJ Case Rep 2022;15:e246648. doi:10.1136/bcr-2021-

246648

\section{SUMMARY}

A 32-year-old homemaker, 28 weeks pregnant, was admitted to a dedicated COVID-19 hospital with a history of dyspnoea for 1 day; oral and nasopharyngeal swabs were positive for SARS-CoV-2 on real-time PCR. She had type 1 respiratory failure and oxygen saturation of $88 \%$, so was put on non-invasive ventilation. Treatment as per guidelines was started. Given her deteriorating condition, a decision to deliver was taken and induction of labour was done. Her condition improved after delivery; but on day 5, she was suspected to have rhino-orbital mucormycosis and antifungals were started. Her condition improved gradually and she was discharged home. This case highlights the importance of individualised decision-making in cases with COVID-19 infection in pregnancy and that prompt treatment of the complications like mucormycosis would be lifesaving.

\section{BACKGROUND}

Pneumonia due to an unidentified cause was first reported in Wuhan, Hubei Province, the People's Republic of China (PRC) in late December 2019. Its clinical characteristics were very similar to those of viral pneumonia. After analysis of respiratory samples, the experts at the PRC Centers for Disease Control declared that pneumonia was caused by a novel coronavirus and labelled as COVID-19. ${ }^{1}$ It subsequently spread to all countries, thus, the WHO declared COVID-19 as a Public Health Emergency of International Concern on 30 January $2020 .^{2}$ The ongoing COVID-19 pandemic caused by SARSCoV-2 has resulted in a global healthcare crisis.

Being a novel infection, knowledge about the effect of COVID-19 on pregnancy outcomes is limited. Initially, the effects of previous human coronavirus outbreaks like the Middle East respiratory syndrome and severe acute respiratory syndrome coronavirus guided the management. In those conditions, poorer outcomes were in pregnant women when compared with the general population. ${ }^{34}$ But earlier reports on COVID-19 $9^{56}$ did not show any increased adverse effects on pregnant women; but after the emergence of the second wave of COVID-19 infection, there is evidence of a higher risk of severe disease and increased intensive care unit (ICU) admissions in pregnant women when compared with non-pregnant COVID-19positive women. $^{78}$

At the same time as the second wave of the COVID-19 pandemic, we witnessed an unusual complication in the infected population, a fungal infection-mucormycosis-which was a lifethreatening condition. There were dilemmas in both diagnosis and treatment of the condition as there were no guidelines.

We present a case of severe COVID-19 infection in pregnancy, which worsened and developed into mucormycosis, who did survive only due to prompt and effective management.

\section{CASE PRESENTATION}

A 32-year-old homemaker who was $28+2$ weeks pregnant (G2P1L1, previous one caesarean section) was admitted with a sore throat and mild headache for 4 days. When she developed breathlessness, she reported to a private hospital, but there was no history of fever and cough. Nevertheless, she was tested and found positive for SARS-CoV-2 by realtime (RT) PCR through oral and nasopharyngeal swabs.

She had no medical history suggestive of respiratory problems and no other medical problems or comorbidities. After being referred from another hospital, she came in an emergency for admission to Maharaja Tukojirao Holkar (MTH) dedicated COVID-19 hospital. On admission, her general condition was unstable. She had dyspnoea on rest, her tachypnoea respiratory rate was $35 / \mathrm{min}$, her oxygen saturation $\left(\mathrm{SpO}_{2}\right)$ was $88 \%$, her pulse rate was $117 / \mathrm{min}$, her blood pressure was $110 / 70$ $\mathrm{mm} \mathrm{Hg}$, and she was not feverish with a temperature of $98^{\circ} \mathrm{F}$. There were bilateral crepitations on chest auscultation and decreased bilateral air entry. Immediately, she was shifted to the ICU and put on non-invasive ventilatory support. Bilevel positive airway pressure (BIPAP) started with fractional inspired oxygen $\left(\mathrm{FiO}_{2}\right)$ of $100 \%$. She was then seen by the multidisciplinary COVID-19 team including a senior obstetrician, respiratory physician and anaesthetist; and according to our institutional guidelines, treatment was started for severe COVID-19 pneumonia.

\section{INVESTIGATIONS}

After admission, as per protocol, X-ray of the chest with abdominal shielding and all investigations for COVID-19 profile were done.

Laboratory changes (table 1) show lactate dehydrogenase $1150 \mathrm{U} / \mathrm{L}, \mathrm{C}$ reactive protein raised to $112 \mathrm{mg} / \mathrm{dL}$, D-dimer $422 \mathrm{ng} / \mathrm{mL}$, serum electrolytes, aspartate aminotransferase and alanine aminotransferase were normal, and absolute leucocyte count raised to $32.3 \times 10^{9} /$ Lshowing infective aetiology, that is, COVID-19 infection. Anterior chest X-ray showed bilateral consolidation with opacities in the lower and middle lobes (figure 1). 


\begin{tabular}{|c|c|c|c|c|}
\hline Investigations & Reference range & Day 1 & Day 5 & Day 20 \\
\hline D-dimer & $0.0-243 \mathrm{ng} / \mathrm{mL}$ & 422 & 254 & 168 \\
\hline Interleukin 6 & $0.0-15.5 \mathrm{pg} / \mathrm{mL}$ & 12.2 & 12.6 & 12.0 \\
\hline $\mathrm{C}$ reactive protein & $<5.0 \mathrm{mg} / \mathrm{L}$ & 112 & 206 & 89 \\
\hline Serum creatinine & $0.5-1.2 \mathrm{mg} / \mathrm{dL}$ & 1.5 & 0.73 & 0.84 \\
\hline Alanine aminotransferase & $0-33 \mathrm{U} / \mathrm{L}$ & 24 & 93 & 68 \\
\hline Aspartate aminotransferase & $5-32 \mathrm{U} / \mathrm{L}$ & 28 & 56 & 37 \\
\hline Platelets & $150-450 \times 10^{9} / \mathrm{L}$ & 180 & 100 & 260 \\
\hline White cell count & $4.8-11.0 \times 10^{9} / \mathrm{L}$ & 32.3 & 26.0 & 17.0 \\
\hline Lactate dehydrogenase & $135-214 \mathrm{U} / \mathrm{L}$ & 1150 & 756 & 584 \\
\hline Triglycerides & $<150 \mathrm{~g} / \mathrm{dL}$ & 145 & 443 & 276 \\
\hline $\begin{array}{l}\text { High Density Lipoprotien } \\
\text { (HDL) }\end{array}$ & $<65 \mathrm{mg} / \mathrm{dL}$ & 34 & 23 & 56 \\
\hline Cholesterol & $<200 \mathrm{mg} / \mathrm{dL}$ & 198 & 254 & 222 \\
\hline
\end{tabular}

\section{TREATMENT}

As per guidelines, she was given antibiotics: intravenous meropenem $1 \mathrm{~g} 12$ hourly, intravenous clindamycin $600 \mathrm{mg} 12$ hourly and intravenous teicoplanin. Antiviral intravenous remdesivir was given. In addition to that, Low Molecular Weight Heparin (LMWH) and injection of methylprednisolone, $160 \mathrm{mg}$ in two divided doses, were given as per national guidelines of COVID-19 treatment of maintaining the $\mathrm{SpO}_{2}$ of 96 on BIPAP $\mathrm{FiO}_{2} 100 \%$.

\section{OUTCOME AND FOLLOW-UP}

On day 3, her condition worsened as her $\mathrm{SpO}_{2}$ fell to $91 \%$ on non-invasive ventilatory support, her pulse rate was $134 / \mathrm{min}$, her blood pressure raised to $150 / 90 \mathrm{~mm} \mathrm{Hg}$ and her blood sugar level was raised to $283 \mathrm{mg} / \mathrm{dL}$; thus, continuous blood sugar monitoring was done and insulin was started. Labour was induced for maternal benefit by mifepristone and misoprostol. For enhancement of fetal lung maturity, she was given a single dose of betamethasone $24 \mathrm{mg}$ before induction. She delivered on day 4 a male baby weighing $1 \mathrm{~kg}$. The baby was shifted to the neonatal ICU and a nasopharyngeal swab of the baby for SARS-CoV-2 was taken which was reported negative. The baby was managed under the care of a senior paediatrician, and was given higher antibiotics, intranasal oxygen support, continuous positive airway pressure, and surfactant. But despite all efforts, the baby could not survive. The baby died after 2 days because of sepsis and prematurity.

On day 5, the patient's condition improved on BIPAP support, with $\mathrm{SpO}_{2} 96 \%$ with $\mathrm{FiO}_{2}$ of $30 \%$. But then she developed

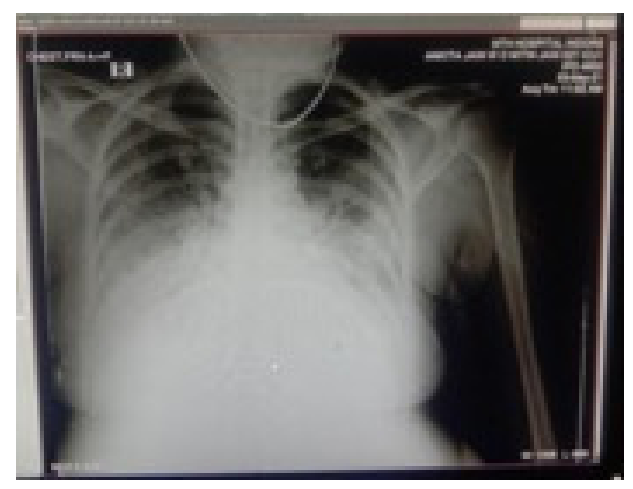

Figure 1 Chest X-ray at the time of admission.

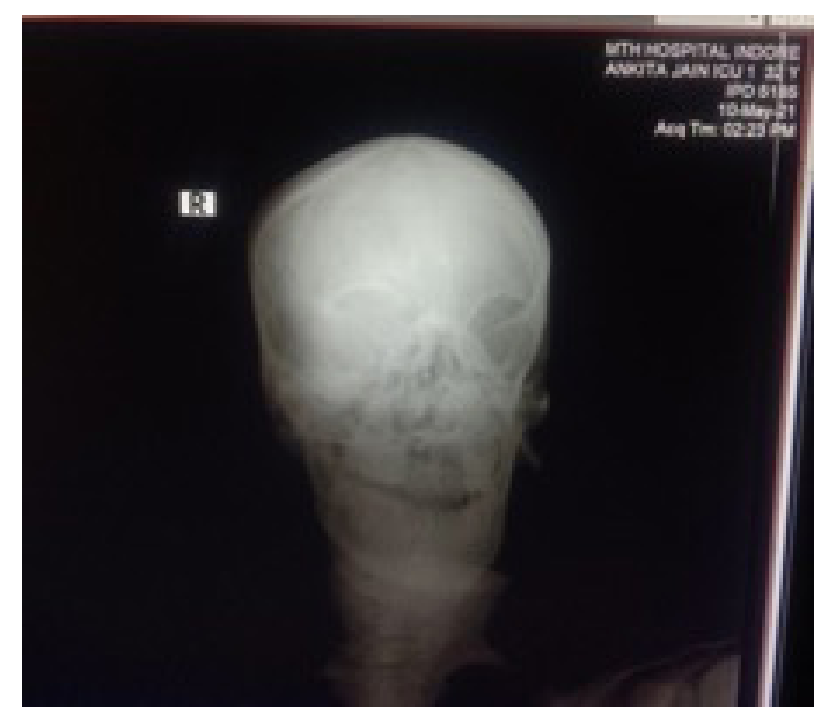

Figure 2 X-ray of paranasal sinuses on day 6.

significant bilateral swelling on her eyelids, and had a headache with black patches around her eyes as well as on her cheek. Ophthalmology examination showed bilateral ptosis. She was examined by an Ear Nose Throat (ENT) surgeon and skin specialist, who suspected mucormycosis. As she was in a morbid condition and on ventilatory support, a biopsy for confirmatory diagnosis could not be taken. Because of suspected mucormycosis (risk factors being pregnancy and high-dose steroids), the multidisciplinary COVID-19 team decided to start intravenous amphotericin $5 \mathrm{mg} / \mathrm{kg}$. Antibiotic eye drops ciprofloxacin and timolol were also given. A paranasal sinus radiograph was done which showed bilateral haziness in ethmoidal and frontal sinuses; the picture was not very clear because the patient was on BIPAP ventilatory support so proper positioning could not be done (figure 2). In the prevailing circumstances at that time, rhino-orbital mucormycosis was a predictable complication of COVID-19 infection.

On day 12, her condition improved; she was shifted from BIPAP to non-rebreathable mask on oxygen at $15 \mathrm{~L} / \mathrm{min}$. Repeat laboratory investigations showed a decreasing trend (table 1). Chest radiograph (figure 3) showed improvement; there was a decrease in bilateral eye swelling and no reports of blurring of vision or headache.

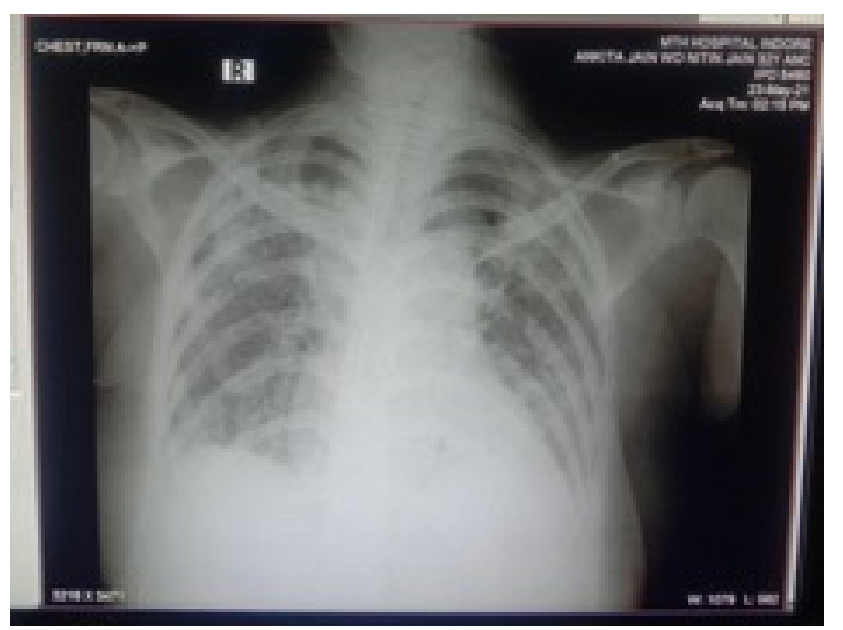

Figure 3 Chest X-ray on day 21. 


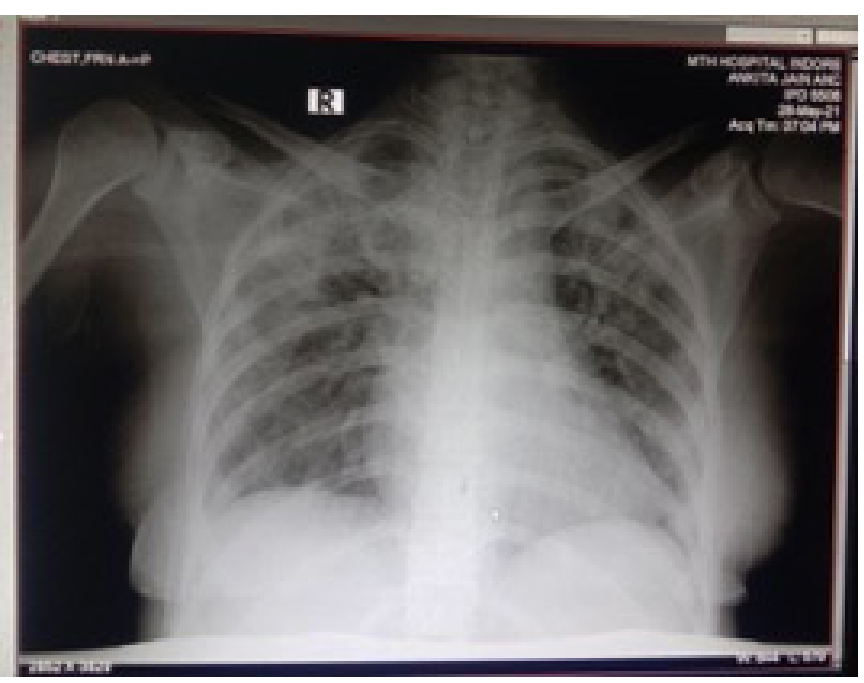

Figure 4 Chest X-ray on day 25 at the time of discharge.

On day 20, she started maintaining saturation on the simple nasal mask at a $6 \mathrm{~L} / \mathrm{min}$ oxygen flow rate. Laboratory investigation showed further improvement (table 1). Repeat chest X-ray and paranasal sinus radiograph were normal (figures 4 and 5). She was discharged home on day 25 after being off oxygen support for 2 days. Her follow-up period was uneventful.

Routine follow-up visits were in post-COVID-19 clinic of the institution, every 15 days for 1 month. As per national protocols, she was kept on intravenous liposomal amphotericin B in initial dose of $5 \mathrm{mg} / \mathrm{kg}$ body weight for 12 days after which tablet posaconazole $300 \mathrm{mg}$ delayed release two times per day for 1 day was given followed by $300 \mathrm{mg}$ daily for 8 days. She had no complications on follow-up visits, recovered well and was in a good condition.

\section{DISCUSSION}

COVID-19 has affected the population worldwide that too drastically, due to mutation in the SARS-CoV-2 virus itself, the pathophysiology of COVID-19 infection is constantly changing. COVID-19 has even affected the obstetric population tremendously especially in the second wave of the pandemic which has led to serious concerns regarding maternal and fetal outcomes. Although there are recommended guidelines (both national and international) regarding delivery and management of

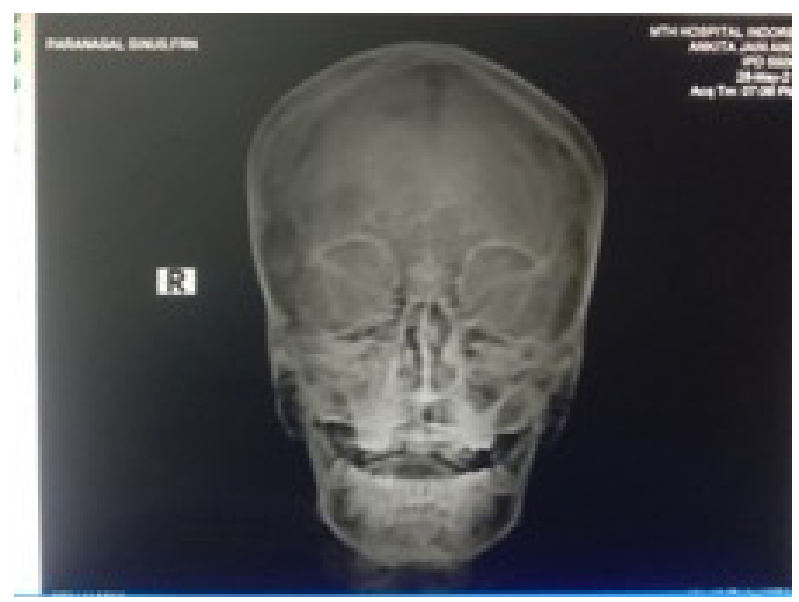

Figure 5 X-ray of paranasal sinuses at the time of discharge on day 25.

Dave A, et al. BMJ Case Rep 2022;15:e246648. doi:10.1136/bcr-2021-246648 complications, due to changes in characteristics of COVID-19 infection, they are constantly changing and evolving. Each case is different in its way and this is the reason why an individualised approach needs to be adopted. This is possible only with multidisciplinary team involvement. An individualised approach would therefore help in optimising maternal and fetal well-being.

We report a case of a second gravida affected with severe COVID-19 infection, Because of respiratory compromise which was not improving despite ventilatory support, a decision for induction of labour was taken. This case emphasises an individualised approach, the importance of early decision-making to induce labour which helped in clinical improvement. Sometimes in some situations, we may have to make decisions for the benefit of the mother. It helped in the improvement of her condition but subsequently, she developed a life-threatening complication. At this stage also, early suspicion and institution of prompt treatment saved her.

Recent studies on COVID-19 infection and management in pregnancy and evidence-based protocols for management ${ }^{6}$ suggest that indications for early delivery must be based on obstetric indications and not the presence of COVID-19 infection. We observed that early induction of labour in a case of severe COVID-19 infection with COX RADS (COVID 19 X-Ray Reporting and Data System) grade 3 changes on X-ray and not improving on non-invasive ventilation helped in decreasing the ventilatory overload and subsequently helped in improving her condition. Respiratory effort and oxygen requirement gradually decreased. Such an individualised approach is essential in all cases. Subsequently, we also need to consider the various methods for induction that may help in early delivery without compromise. In our case, the use of mifepristone-misoprostol combination was not only safe, but also very effective and helped to decrease complications that may be associated with caesarean delivery. A woman who is already on non-invasive ventilatory support is not a good candidate for operative delivery. After termination of pregnancy, $\mathrm{SpO}_{2}$ improved significantly and coverage of higher intravenous antibiotics, antiviral drug remdesivir and steroids in the postpartum period decreased the inflammatory process and helped in recovery. The baby was a male child with a weight of 1 $\mathrm{kg}$, was negative on RT PCR done within 24 hours of birth, was kept in the neonatal care unit, but unfortunately did not survive. Studies have shown that pregnant women who had underlying hypertension and raised blood sugar levels had raised proinflammatory markers and were at increased risk of severe illness and respiratory diseases. ${ }^{9}$ Although our patient did not have a history of raised blood sugar during treatment, her blood sugar was at a very high level and regular use of insulin was required to maintain it in the normal range.

Various COVID-19 complications are known but a lifethreatening complication which surged during the second wave of COVID-19 infection was mucormycosis. Fungal infections, including mucormycosis, aspergillosis and invasive candidiasis, have been reported in patients with severe COVID-19 or those recovering from the disease and have been associated with severe illness and death.

Mucormycosis is a fungal infection that results in respiratory or skin infections and the symptoms of which are similar to COVID-19. It may cause cough, fever, headache, nasal congestion, and after the development of complications, it may affect the eyes, face, central nervous system, and sinuses. It leads to the dreadful possibility of paralysis, severe respiratory pneumonia, seizures, and in rare cases, blindness and death of patients. ${ }^{10}$ Pregnant women are at high risk after COVID-19 infection as they are highly susceptible to coinfection, so it is recommended 
that strict round-the-clock vital monitoring, along with the close observation of the patient's skin infections, especially newly appearing blisters, should be considered. Opinion of a dermatologist is essential, as many of these patients are on non-invasive ventilatory support and are in critical care units so they are immobilised for days and may get infected. They may develop other iatrogenic infections as well. Newly developed cough, nasal congestion or headache in a patient already having COVID-19 pneumonia must be investigated for any coinfection along with mucormycosis. ${ }^{10}$ Once identified, the patient needs to be promptly treated with antifungal medications: intravenous amphotericin B, oral posaconazole and surgery, if required.

In our case, we suspected that our patient had rhino-orbital mucormycosis based on her symptoms; because she was on BIPAP at that time, a biopsy could not be taken for a definitive diagnosis. We started antifungal amphotericin $\mathrm{B}$ in addition to the treatment she was already receiving. Then gradual improvement in her symptoms of pain and swelling confirmed the diagnosis. In India, during the second wave of the corona pandemic, there was an upsurge of mucormycosis according to a study. The risk factors for this complication were steroid abuse, improper usage of oxygen and undiagnosed diabetes worsening because of steroids. ${ }^{11}$

Though COVID-19 has affected many pregnant women, most of them were asymptomatic; some had a severe and critical illness, and their management needs to be individualised. Using the best possible individualised approach by a multidisciplinary team in these situations can be lifesaving. ${ }^{12}$ COVID-19 is associated with a significant incidence of secondary infections, both bacterial and fungal, probably due to immune dysregulation. Additionally, the widespread use of steroids/monoclonal antibodies/broad-spectrum antibiotics as part of the armamentarium against COVID-19 may lead to the development/exacerbation of pre-existing fungal diseases. Physicians should be aware of the possibility of invasive secondary fungal infections in patients with COVID-19 infection especially in patients with pre-existing risk factors and should enable early diagnosis and treatment with

\section{Learning points}

- Current evidence from various studies does mention that management of pregnancy with COVID-19 is essentially based on guidelines for COVID-19 as a whole.

- Despite ongoing evidence, it has been seen that continuation of pregnancy in those pregnant women who have severe disease and lung infection may cause respiratory compromise, which may be fatal.

- An individualised approach needs to be adopted as early delivery will help in improvement in such cases.

- Complications of COVID-19 require prompt identification and treatment. the subsequent reduction of mortality and morbidity. The use of therapeutic agents should be monitored to achieve a therapeutic effect at the lowest dose and shortest duration. The use of broad-spectrum antibiotics, especially in the absence of infection, should be re-evaluated. ${ }^{13}$

Contributors All authors made substantial contributions to the elaboration of the work. AD - conception and design of the work, drafting the manuscript and bibliographical research. PJ and PK - patient management, revision of the manuscript and bibliographical research. SJ—revision of the manuscript critically for important intellectual content. The final version to be published was approved by all authors.

Funding The authors have not declared a specific grant for this research from any funding agency in the public, commercial or not-for-profit sectors.

Competing interests None declared.

Patient consent for publication Obtained.

Provenance and peer review Not commissioned; externally peer reviewed.

Case reports provide a valuable learning resource for the scientific community and can indicate areas of interest for future research. They should not be used in isolation to guide treatment choices or public health policy.

\section{ORCID iD}

Anupama Dave http://orcid.org/0000-0002-6418-3892

\section{REFERENCES}

1 WHO. Rolling updates on coronavirus disease (COVID- 19), 2020. Available: https:// www.who.int/ emergencies/diseases/novel-coronavirus-2019/events-as- they-happen

2 WHO. Coronavirus disease (COVID-19) outbreak situation, 2020. Available: https:// www.who.int/emergencies/diseases/novel-coronavirus-2019

3 Alfaraj SH, Al-Tawfiq JA, Memish ZA. Middle East Respiratory Syndrome Coronavirus (MERS-CoV) infection during pregnancy: Report of two cases \& review of the literature. J Microbiol Immunol Infect 2019;52:501-3.

4 Di Mascio D, Khalil A, Saccone G, et al. Outcome of coronavirus spectrum infections (SARS, MERS, COVID-19) during pregnancy: a systematic review and meta-analysis. Am J Obstet Gynecol MFM 2020;2:100107.

5 Rasmussen SA, Smulian JC, Lednicky JA, et al. Coronavirus disease 2019 (COVID-19) and pregnancy: what obstetricians need to know. Am J Obstet Gynecol 2020;222:415-26

6 López M, Gonce A, Meler E, et al. Coronavirus disease 2019 in pregnancy: a clinical management protocol and considerations for practice. Fetal Diagn Ther 2020;47:519-28.

7 Allotey J, Stallings E, Bonet M, et al. Clinical manifestations, risk factors, and maternal and perinatal outcomes of coronavirus disease 2019 in pregnancy: living systematic review and meta-analysis. BMJ 2020;370:m3320.

8 Collin J, Byström E, Carnahan A, et al. Public Health Agency of Sweden's Brief Report: Pregnant and postpartum women with severe acute respiratory syndrome coronavirus 2 infection in intensive care in Sweden. Acta Obstet Gynecol Scand 2020;99:819-22.

9 Hojyo S, Uchida M, Tanaka K, et al. How COVID-19 induces cytokine storm with high mortality. Inflamm Regen 2020;40:37

10 Mekonnen ZK, Ashraf DC, Jankowski T, et al. Acute invasive rhino-orbital mucormycosis in a patient with COVID-19-Associated acute respiratory distress syndrome. Ophthalmic Plast Reconstr Surg 2021;37:e40-80.

11 Bhogireddy R, Krishnamurthy V, Jabaris S SL, et al. Is mucormycosis an inevitable complication of Covid-19 in India? Braz J Infect Dis 2021;25:101597.

12 Mignogna MD, Fortuna G, Leuci S, et al. Mucormycosis in immunocompetent patients: a case-series of patients with maxillary sinus involvement and a critical review of the literature. Int J Infect Dis 2011;15:e533-40.

13 Mehta S, Pandey A. Rhino-Orbital mucormycosis associated with COVID-19. Cureus 2020;12:e10726. 
Copyright 2021 BMJ Publishing Group. All rights reserved. For permission to reuse any of this content visit https://www.bmj.com/company/products-services/rights-and-licensing/permissions/

BMJ Case Report Fellows may re-use this article for personal use and teaching without any further permission.

Become a Fellow of BMJ Case Reports today and you can:

- Submit as many cases as you like

- Enjoy fast sympathetic peer review and rapid publication of accepted articles

Access all the published articles

Re-use any of the published material for personal use and teaching without further permission

Customer Service

If you have any further queries about your subscription, please contact our customer services team on +44 (0) 2071111105 or via email at support@bmj.com.

Visit casereports.bmj.com for more articles like this and to become a Fellow 